\title{
"Ni tan pronto ni tan tarde". La incorporación anticipada de Pinochet al golpe de estado de 1973. Documentos estadounidenses
}

Not so soon or so late. Pinochet's early incorporation in the coup d'état of 1973. US documents

\section{RESUMEN:}

En este artículo se analizan y publican documentos desclasificados de las agencias estadounidenses de inteligencia y algunos testimonios y antecedentes chilenos que demuestran, de manera inobjetable, que el general Augusto Pinochet se encontraba ya integrado al complot para derrocar a Salvador Allende, en la primera semana de septiembre de 1973, y posiblemente desde el 20 de agosto, sino antes.

Palabras clave: Complot-1973-A, Pinochet-P, Carvajal-G, Leigh-I, Huerta, Ejército, Armada, Fuerza Aérea, CIA-DIA.

\section{ABSTRACT:}

In this article, declassified documents of the US intelligence agencies and some Chilean testimonies and antecedents are analyzed and published that show, in an unobjectionable way, that General Augusto Pinochet was already involved in the plot to overthrow Salvador Allende, in the first week September 1973, and possibly from August 20, if not earlier.

\footnotetext{
* Académico Universidad de Concepción y Universidad de Chile. ORCID: https://orcid.org/0000-0001-5667-5515. Correo electrónico: etellez@udec.cl
} 
Key words: Plot-1973-A, Pinochet-P, Carvajal-G, Leigh-I, Huerta, Army, Navy, Air Force, CIA-DIA.

Recibido: mayo 2021

Aceptado: septiembre 2021

En el museo (el lector deberá suponerlo infinito) de las extrañezas humanas, cualquier hijo de vecino podrá cerciorarse, si logra llegar hasta el escaparate indicado, que hasta los golpes de estado gozan de una historia oficial. El putsch de 1973, por supuesto, tiene la suya. Una en la que Augusto Pinochet aparece acoplándose, vacilante y a última hora (en la media tarde del 9 de septiembre), al levantamiento que sepultó el "experimento marxista chileno", según la expresión de R. Moss. Tal es la ecuación aceptada por una interminable cadena de autoridades, de distinto credo. La defienden por igual N. Davis y G. Vial Correa. O lo mismo J. Garcés que A. Angell. Entre muchos. Ninguno, sin embargo, se ha tomado el trabajo de sondear la dudosa consistencia de esa teoría. Poco ha importado que las eficaces síntesis empíricas de Kornbluth y C. Basso, la señera antología documental de Soto y Villegas y otros archivos liberados últimamente coloquen en serio aprieto aquel presupuesto, ahora convertido en sentido común y profesión de fe. Ello da cuenta de porqué las recientes novedades literarias sobre la experiencia de la Unidad Popular y su final wagneriano no traigan al respecto, precisamente, novedades.

Lo cierto es que los archivos exhumados de su tumba fiscal muestran un desarrollo muy distinto de la intriga que tomó impulso en julio de 1973 y concluyó con el golpe de estado unificado del martes 11, tres meses después. En lo inmediato, esos papeles nos confirman cuatro ángulos inobjetables: 1. Que Pinochet se unió a la conspiración, cuando menos, hacia el final de la tercera semana de agosto de 1973; 2. Que negoció su lugar en el golpe a lo largo de la primera semana de septiembre con la cúpula máxima del levantamiento castrense (fijado, con pleno conocimiento de Pinochet, para el 10 de septiembre) 3; Que se encontraba alineado, ya para el viernes 7 de septiembre, con las tres grandes fuerzas que iban a alzarse contra la Unidad Popular el lunes 10, aunque terminaron haciéndolo al día siguiente; 4. Que la junta del domingo 9 en su casa giró en torno, precisamente, a notificarse del cambio abrupto de fecha, decidida por la dirección insurrecta de la marina de guerra, apenas esa misma mañana, y a obtener la aceptación formal de Leigh y el suyo a este cambio imprevisto en el itinerario del levantamiento. Si de él hubiera dependido, Pinochet lo hubiera lanzado el viernes 14 de septiembre, en virtud de meras conveniencias tácticas.

Es cierto, también, que el general de división aportó en demasía a generar la imagen falaz de un soldado pudoroso compelido por sus pares a unirse a una insurrección desesperada, que 
tenía mucho de improvisado. Sus memorias persiguen posar en el alma de su lector esta idea sedante $^{1}$. Sin embargo, tal clase de argumentos forma parte de un discurso doloso que Augusto Pinochet urdió y administró con asombrosa pericia, al punto de timar a su mentor, el general Carlos Prat, al gobierno de Allende y, también, a posibles aliados. Una parte de este doble discurso se revestía de tonalidades lastimeras y humanitarias. A últimos de agosto, v.gr., le endilgó a un incógnito informante de los servicios estadounidenses ( $\mathrm{X}$ le llamaremos) una homilía semejante ${ }^{2}$. El arcano visitante y colocutor del comandante en jefe del ejército (CJE) se encontró con un anfitrión "resignado", le dijo, a la eventualidad de tener que conducir un golpe de estado, casi inevitable, contra el gobierno trastabillante del presidente Allende y la Unidad Popular. No lo haría antes, le recalcó a X, de haber agotado todas las instancias factibles de producir un arreglo institucional de la crisis sistémica en que se hallaba sumergida la nación ad portas de la primavera de 1973. Tanta era la confianza del oficial criollo con su huésped, que se atrevió a mostrarle un costado vulnerable de sí mismo. A X le pareció que el general estaba "aterrado" (frightened) frente a la alta probabilidad de que todo se fuera al diablo y terminará en una "matanza" (bloodshed). Desaprobó, dentro de esta lógica argumentativa, que el ejército se embarcara en un golpe de estado. Lo desnaturaliza, dejó traslucir. No era esa su misión y solo autorizaría una cosa tal si las restantes posibilidades se encontraran agotadas. Por ejemplo, si la inmensa mayoría de la ciudadanía y/o los partidos de la oposición, en bloque, lo pidieran ${ }^{3}$. Lo cual indica que al CJE no le resultaba bastante la declaración del 22 de agosto de la cámara baja, cuyo eje giraba en torno a la inconstitucionalidad del gobierno y a la intervención de las FFAA en la contingencia nacional. Pese a ello no arriesgó decir qué clase de entendimiento propiciaba. Esperaba, insinuó, que esa respuesta proviniera de la presidencia y/o de los partidos mayoritarios representados en el congreso. No le correspondía a los institutos armados decirlo. Pinochet, empero, descreía. Estaba escéptico acerca de que la clase política atinara con una salida razonable. De igual forma, sostenía que un derrocamiento 'justificado', precisaba de un reclamo generalizado de la opinión pública en favor de tamaña opción: el clamor irrebatible de la calle". Insistía, empero, de nuevo, en un prerrequisito (¿resquicio?) que comentara con el coronel Gerald Sills, jefe de inteligencia del comando sur de los EE. UU. (Panamá) en febrero pasado, un semestre antes. Sills, se las arregló, -de manera imprudente a juicio del embajador de Nixon en Chile, Nathaniel Davis- para interrogar al general chileno acerca de "cuándo pensaba actuar" (conducir un golpe). La respuesta de Pinochet fue la propia de una mente ladina. Las FFAA criollas "no actuarían hasta que la gente saliese a las calles a pedirlo", le

\footnotetext{
1 Pinochet, Augusto. 1990. Camino recorrido. Memorias de un soldado, Santiago, Impr. del Instituto geográfico militar, tomo I. p. 280; y Pinochet, A. 1999. Diálogos con su historia. Conversaciones inéditas con María Eugenia Oyarzún, Santiago, Sudamericana, pp. 146 - 149.

${ }^{2}$ Coup cables, National Security Council (NSC) Files, Augusto Pinochet files, box 777-778, fs. 20-4.

${ }^{3}$ lbídem.
} 
respondió a Sills. "Si actuamos demasiado pronto toda la gente se uniría contra nosotros" 4 . Un diálogo así de incompatible con los respetos y subordinación debidos al poder constituido, delatan que ya en el verano del '73 se dejaba galantear por la inteligencia extranjera y sacaba cuentas acerca de la base popular necesaria para afianzar un levantamiento militar.

El general en jefe se reservó otros arcanos. No le dijo a su visita, p. e., que ya contaba con un acabado plan operativo, dirigido a neutralizar los bastiones del "poder popular" y a destruir las organizaciones de izquierda en el contexto de un golpe de estado. $O$ que estaba en estrecha connivencia con el contralmirante Patricio Carvajal, cerebro de un núcleo clandestino destinado a preparar el derrocamiento del gobierno, a fin de sumarse a la conjura en el momento indicado. El contralmirante Ismael Huerta, uno de los complotadores prominentes de la armada, cuenta en sus extensas memorias que el almirante Patricio Carvajal, cerebro mayor de la conjura de 1973, le confirmó la noche del 20 de agosto de ese año cruento, estando Huerta en Valparaíso, mediante un mensaje manuscrito y en lenguaje cifrado remitido desde Santiago con el capitán de fragata Luis Iturriaga, una noticia decisiva para la causa. En un párrafo antecedido de tres cruces el papel señalaba, taxativo: "Pinochet (totalmente) decidido". A ser parte del complot, naturalmente. Carvajal añadía, además, una nueva tranquilizadora, emanada con seguridad del mismo personaje: "el Ejército se plegará al acuartelamiento que dispongan la Fach o la Armada" ${ }^{5}$. Sobre el comandante en jefe del ejército, Carlos Prats, profetizaba, "tarde o temprano Prats tendrá que dejar el ejército", anticipando un desenlace previsible, producido tres días después ${ }^{6}$. Pinochet mismo, le confesó Carvajal a Huerta y este a su diario, que el clímax nacional no tenía "más que una solución" (derrocamiento de Allende) ${ }^{7}$. EI CJE, es taxativo al momento de aclarar quién era su intercesor con los círculos extremos de la marina de guerra: "El almirante Patricio Carvajal, jefe del estado mayor de la defensa nacional, era mi contacto con la armada", admite con economía de adjetivos el general ${ }^{8}$.

\section{$* * *$}

Desde comienzos de julio de 1973, las potentes fracciones anticomunistas de la marina, fuerza aérea ( $F A C h$ ) y ejército, convergieron en impulsar un proyecto insurreccional definitivo contra el régimen de la Unidad Popular, agitación que se canalizó en un programa subversivo colocado bajo la dirección del contralmirante Patricio Carvajal, auténtico cerebro de la maniobra, el cual venía trabajando en la iniciativa desde mucho antes. Carvajal, a cargo de la jefatura del comando conjunto del estado mayor de la defensa nacional (EMDN), usó esa repartición como centro de coordinación del golpe de estado, fuertemente apoyado en el ala sediciosa de los generales y almirantes aglutinados en el "consejo de los 15". Compuesto de

\footnotetext{
4 Davis, Nathaniel. 1986. Los dos últimos años de Salvador Allende, Barcelona, Plaza \& Janes, pp. 154 y 385, nota 50.

${ }^{5}$ Huerta, 1988. Volvería a ser marino, volumen II, Santiago, Andrés Bello, p. 78.

6 lbídem.

7 Ibíd., 79 y nota 9; también, Pinochet, 1999. Augusto Pinochet: Diálogos con su historia, p. 150.

8 Pinochet,1999. Augusto Pinochet: Diálogos con su historia, p.150.
} 
cinco altos oficiales (almirante o generales) de cada una de las tres ramas de la defensa, esta nueva instancia, autorizada del gobierno, debía abocarse a la formulación de un nuevo diseño de seguridad nacional, en un escenario político en vertiginoso deterioro tras el motín de los tanquistas del batallón Blindado 2, al mando del teniente-coronel Roberto Souper, el 29 de junio de 1973. La fracción más radical del consejo, sin embargo, dedicó su quehacer a secundar, bajo cubierta, al grupo faccioso del EMDN, que en un bimestre (julio-agosto) terminó de montar un nuevo programa de seguridad -el plan "Lautaro"-, una partitura de suyo engañosa. En realidad, la propuesta conformaba una maleta de doble fondo. El compartimento visible del diseño presentada a firma de la autoridad respectiva el 17 de agosto, pretendía ser un modelo preventivo, destinado a fortalecer las capacidades de defensa del gobierno ante una abstracta amenaza "insurgente", de cualquier signo ${ }^{9}$. La casilla oculta de "Lautaro", no revelada por la dirección putschista, escondía un exhaustivo programa de golpe ofensivo, orientado a derrocar al gobierno con el concurso estrecho de las tres fuerzas de la defensa nacional ${ }^{10}$. Sin embargo, el nodo conspirativo del EMDN/consejo de los 15, actuaría como instancia superior de coordinación de las tres armas intervinientes, que no estarían sujetas a un plan operativo común. A la inversa, el comando en jefe del EMDN instruyó a los estados mayores respectivos de cada rama involucrada en el movimiento, preparar proyectos tácticos separados (si bien concurrentes) a emplearse cuando el alzamiento general, en las jurisdicciones en que les correspondía actuar. Pinochet, que venía trabajando en ello con anterioridad (mayo), junto al general $\mathrm{H}$. Brady, y una avezada fuerza de tarea, reforzada con estudiantes sobresalientes de la academia de guerra del ejército ${ }^{11}$, coronó su plantilla a finales de agosto, abocada a la aniquilación de la base partidaria de la UP, la izquierda radical (MIR) y los reductos físicos del "poder popular" mediante una ofensiva fulminante en la capital, sede del Estado ${ }^{12}$.Poner en duda, como se ha hecho, esta planificación, no resiste análisis ${ }^{13}$. Los afanes golpistas de Pinochet y la voluntad de poner en obra su programa de exterminio se expresan en un simple antecedente recogido por la $\mathrm{CIA}$ en los intersticios del ejército. El mismo día en que recibió sus despachos de comandante en jefe (24 de agosto), Pinochet se jactó en una reunión privada, y en presencia de un escucha de la Agencia, que la institución planificaba "borrar" (wipeout o

\footnotetext{
9 Pérez Carrillo, D. 2006, "La fronda militar", Documento de Trabajo, 82, septiembre, Inap Universidad de Chile, pp. 145-148.

10 Ibídem.

${ }^{11}$ Cfr. González Camus, Ignacio. 1988. El día en que murió Allende, Santiago, Cesoc, p.41.

12 Espinoza, G. 1998. "Allende. 25 años", Especial de El Siglo, Santiago, 11/17 de septiembre de 1998, pp. 6 - 7; Varios, 1995. "11 de septiembre, operación militar", Especial de El Siglo, Santiago, 15 de septiembre de 1995, p. 10. Fontaine, A. y C. Zegers, 1974. "Como llegaron las Fuerzas armadas a la acción del 11 de septiembre de 1973", suplemento de El Mercurio, Santiago, 11 de septiembre de 1974; González Camus, I. 1988. El día en que murió Allende, pp. 41 - 43; Toro, C. 1995. "El general Prats pudo evitar el golpe", Especial de El Siglo, Santiago, 15.09.1995. 8-9. Téllez, E. 2021. Una guerra relámpago (Mss.), Santiago; Whelan, James. 1993. Desde las cenizas. Vida, muerte y transfiguración de la democracia en Chile 1833-1988, Santiago, Zig-Zag. caps. 7 y 8.

${ }^{13}$ González Mujica, Mónica. 2000. La conjura. Los mil y un días del golpe, Santiago, Ediciones B.
} 
"aniquilar", según sea la traducción) al MIR, sobre el cual proyectaba aplicar una política "muy dura"14.

"Lautaro", de consiguiente, se constituyó en un paraguas extendido, bajo cuya alargada comba se aplicaron planes de acción flexibles y de gran autonomía, aunque bien orquestados desde el EMDN ${ }^{15}$.

Lo anterior parece tener mucha relación con un elaborado informe de la $\mathrm{ClA}$ concerniente a cómo se consumó el tramo final del complot. Se trata de un balance formado por la oficina local del órgano estadounidense, entre el 11 y el 16 de septiembre, basada en fuentes profundas de la conspiración, y que muestra al CJE A. Pinochet comprometido de pleno en el tinglado, con mayor anticipación a lo imaginado:

"A mediados de agosto de 1973, señala el informe, las fuerzas armadas iniciaron la preparación para derrocar al ex presidente Salvador Allende; para esta tarea, organizaron un "equipo especial de coordinación", compuesto por tres delegados de cada servicio militar, con el rango máximo de general o almirante; posteriormente, civiles cuidadosamente escogidos, fueron incorporados en el equipo ...Este equipo de coordinación preparó el plan de derrocamiento del gobierno de la Unidad Popular (UP) y el 1 y 2 de septiembre fue explicado a los comandantes en jefe (CEJ) del ejército y de la fuerza aérea y al almirante José Merino. El plan fue aprobado por ellos, y se dieron órdenes de hacer los preparativos para emprender la acción el 10 de septiembre, a una hora que sería establecida por el general Pinochet, comandante en jefe del ejército, que fue elegido como jefe del grupo". Empero, "por varias razones, particularmente por algunos problemas organizativos en la red de radio y televisión de las fuerzas armadas y carabineros, el golpe fue pospuesto hasta la madrugada del 11 de septiembre" ${ }^{16}$. Es palpable, por el cambio de redacción, que los funcionarios de la Agencia, en los tramos siguientes de la reseña, pasan a citar pasajes textuales del proyecto golpista aprobado el 1 y 2 de septiembre: "El plan aprobado fue el siguiente: Al amanecer del 11 de septiembre, la marina tomaría posesión de Valparaíso y Viña del Mar, y emitirá un ultimatum al presidente Allende ... La armada y la fuerza aérea (Fach) se acuartelarán en primer grado de alerta, a partir de las 7.30 A.M. del 11 de septiembre...Los carabineros serían neutralizados por un ... nuevo director general, que sería el general César Mendoza. Mendoza ordenaría retirar los carabineros del palacio [la Moneda], de la oficina del intendente de Santiago y de la residencia presidencial de Tomás Moro. Además, carabineros daría apoyo a las fuerzas armadas... Sería instaurada una junta

\footnotetext{
${ }^{14}$ Directorio de operaciones de la ClA, 25.08.73, n.9, fs. 4; documentos liberados por el Project Chile, tranche 1, 1999. 15 Pérez Carrillo, D. 2006. "La fronda militar", Documento de Trabajo, 82, septiembre, Inap Universidad de Chile, pp. 145 y ss.

${ }^{16}$ Cablegrama de la CIA, de 08.09.73, Coup cables, NSC Files, A. Pinochet files, boxes 777-771, fs.31 - 32.
} 
de gobierno, compuesta por los tres comandantes en jefe y el director de carabineros, la cual funcionaría en el ministerio de defensa y desde allí, a las 9:00 AM, o cuando contacte a Allende, emitirá un ultimatum exigiendo la entrega del poder a ella"17.

La relación no deja espacio a dubitación alguna, máxime que se vale del prospecto del golpe (en original o duplicado), anterior a su consumación, con una precisión aditiva: La alusión a un plan de acción urdido desde el 15 de noviembre en adelante, únicamente puede referirse a la última etapa de las adecuaciones que se le formularon al plan "Lautaro", retocado hasta el propio día 10 de septiembre, y no al proyecto total, comenzado, como se dijo, en los primeros días de julio.

En el curso de la semana hábil que siguió a las jornadas sediciosas del 1 y 2 de septiembre, a la CIA y a los miembros de la misión militar de los EE. UU. en Santiago (el MilGroup de la embajada norteamericana), instalada cómodamente en el seno de las FFAA chilenas -virtudes del PAM ('Pacto de ayuda mutua') y otros convenios jurídicos bilaterales- se les volvió tangible la participación del general Pinochet en la trama golpista. Uno o dos días antes que el contralmirante José T. Merino se entrevistara con el presidente Allende en la Moneda, cita fijada para la tarde del viernes 7 de septiembre y reservada a tratar el nombramiento de Merino en la comandancia en jefe de la armada, en reemplazo del vicealmirante Raúl Montero, su jefe titular, muy cuestionado por la oficialidad naval, un parte de la ClA (Santiago) volvió a acreditar el lugar de Pinochet en la maquinación.

Según un taxativo cablegrama del órgano de inteligencia del 7 de septiembre, pero referido a movimientos ocurridos en días previos, uno de sus contactos o allegados (con alta probabilidad, un oficial superior del MilGroup estadounidense) logró tratar sobre los preparativos del golpe con Pinochet y Leigh. " ... [Identidad tachada] había conversado con Augusto Pinochet, comandante en jefe del ejército y el comandante en jefe de la fuerza aérea, Gustavo Leigh en [tachado]... septiembre y ellos están de acuerdo en iniciar un movimiento militar contra el gobierno de Allende [tachado] el 10 de septiembre. Esta acción tendrá lugar aunque el presidente Salvador Allende decida remover al comandante naval Raúl Montero antes del 10 de septiembre y reemplazarlo por el almirante José Merino, comandante de la primera zona naval en Valparaíso". El levantamiento estaba decidido, sin quedar condicionado a si ocurrían o no los cambios institucionales demandados por la levantisca oficialidad de la marina; lo cual se esperaba sucediera durante la reunión agendada entre Merino y Allende, a comienzos de la tarde del viernes 7 de septiembre. Transferencia de mando que, vaticinaba la $\mathrm{CIA}$ (correctamente), no ocurriría ${ }^{18}$. El alistamiento definitivo se produjo la tarde del viernes. Un preciso sumario de la embajada estadounidense a Washington, firmada por un tal Thompson,

\footnotetext{
${ }^{17}$ Ibídem, f. 2.

18 Dirección de operaciones de la CIA, cable informativo de inteligencia, distribuido el 07.09.1973, Coup cables, NSC Files, A. Pinochet files, boxes 777-778, fs. 30-1.
} 
funcionario de esa delegación, notificó los resultados de "key intelligence reports of sep 7", con las últimas movidas al interior de las FFAA. Sobre el particular, la embajada clarificó, en el apartado $D$ del mensaje secreto, que "el almirante Carvajal, jefe del estado mayor conjunto de la defensa, el comandante en jefe de la fuerza aérea, Leigh, el comandante en jefe del ejército, Pinochet, se reunieron el 7 de septiembre por la tarde y acordaron actuar contra el gobierno a las 0800 del lunes 10 de septiembre, sea lo que sea que haga Allende" ${ }^{19}$. Se ratificaba la fecha adoptada en las conversaciones del 1-2 de septiembre, en lo cual no tuvo ninguna incidencia la desesperada convocatoria a un plebiscito no vinculante que haría el presidente Allende el 11 de septiembre. J. Garcés sembró la tesis de que el golpe se adelantó para el martes 11 no bien Allende notificó a Pinochet su determinación de llamar a referendo ese día. Empero, el derrocamiento estaba acordado desde mucho antes. En realidad, los conspiradores retrasaron el día en vez de anticiparlo. El supuesto de Garcés se estrella contra la documentación.

La noticia se divulgó en Washington el día 7 pero es indisputable -la información transmitida lo esclarece- que alude a hechos generados con anterioridad a esa fecha. Tenor que, como se ve, ajusta por entero con los sucesos registrados el 1 y 2 de septiembre (aprobación de los procedimientos y objetivos del plan del golpe). Otro comunicado de la Agencia (Santiago) confirma que la marina de guerra, con apoyo de la FACh y unidades del ejército lanzarían una insurrección escalonada el lunes 10, materia de conversación entre Leigh y Pinochet. Este alegaba que no se opondría a la acción de la marina, si bien no se explicita si daría su apoyo el movimiento, ni tampoco queda bien definido el compromiso de los generales de la institución con la asonada. Empero, estas lagunas acaso son el efecto de los vacíos de la fuente consultada, que en este punto se confiesa insegura de todo. También pudiera estar reflejando la molestia de Pinochet y el cuerpo de generales con el clima anárquico imperante, a la sazón, en la armada. La flota se había amotinado súbitamente contra Montero, alertando a los sensores del gobierno, una parte de la oficialidad quería iniciar ya mismo la sublevación, y Merino, a última hora, llevado de un interés personal (ser nombrado jefe titular de la marina de guerra), pretendía trasladar la fecha acordada para el golpe, al miércoles siguiente. La posición de la armada inyectaba desorden a un proyecto hasta ayer coherente, $y$, de paso, activaba el radar del ejecutivo. No es de desestimar que la actitud de Pinochet y los generales, si en verdad sucedió, fuese un intento, no sabemos si fallido o fructífero, de presionar a la armada a contenerse y estar a tono con los planes. Leigh notificó a su círculo que del 8 al 10 de septiembre seguiría las tratativas con los generales de tierra, uno de cuyos puntos gravitaba, es notorio, en torno a la suplantación del día $D$, que no gustaba mucho en el ejército ${ }^{20}$. Sin embargo, las suertes estaban echadas. El viernes 7 Pinochet y una delegación del ejército volaron en

\footnotetext{
19 Télex de la embajada de los EE. UU. en Santiago a Secretaría de Estado, 07 de septiembre de 1973, Coup cables, NSC Files, A. Pinochet files, box. 1, f. 6 .

${ }^{20}$ Cablegrama de la CIA, de 08.09.73, Coup cables, NSC Files, A. Pinochet files, boxes 777-771, fs.31-32.
} 
helicóptero hasta Valparaíso para ultimar detalles, en reunión reservada con el almirantazgo rebelde, acontecida en el recinto de la escuela naval ${ }^{21}$; viaje, cita y materias detectados por funcionarios de la presidencia y los servicios de inteligencia del ministerio del interior y del partido socialista, implantados en la ciudad-puerto ${ }^{22}$. Esa noche, la filial local de la división del área occidental de la DIA (Defense Intelligence Army), estructura sutil del aparato de informaciones del ejército norteamericano, con estrechas relaciones en las fuerzas de defensa chilenas, basada en antecedentes seguros, transmitió a Washington las novedades de la jornada, que la división divulgó en un sumario distribuido al día siguiente. Se refrendaba allí que "los tres servicios [ramas de las F.F.A.A.], según informes, acordaron proceder contra el gobierno el 10 de septiembre...". Ratificaba, luego, que "el golpe parece contar con el apoyo de todos los comandantes de servicio [instituciones], una situación que Allende había sido capaz de esquivar durante el año pasado"23. Merino, comandante en jefe de hecho, y Leigh y Pinochet, jefes titulares, encabezaban el levantamiento castrense.

La junta en casa de Pinochet del domingo 9 de septiembre se centró, de conformidad con la letra y el espíritu del famoso "papelito" cursado por el almirante Merino, en debatir el cambio abrupto de fecha, responsabilidad del almirantazgo, determinación tomada recién durante la mañana de ese mismo día, y que los jefes de la marina querían comunicar, por seguridad, a través de medios humanos (almirante Sergio Huidobro y capitán Ariel González). Si se repasa con imparcialidad y atención la nota de Merino, salta a la vista que los planes estaban ya formados y entendidos previamente. El hombre de mar -léase- los da por sabidos de antemano. De lo contrario, habría entrado a explicarse, cosa que nunca hace, por innecesaria. La novedad estaba en la fecha, martes 11 . Mutaba el día, no los hechos.

\section{Documentos}

\section{Un general horrorizado}

Fecha: 6 de septiembre de 1973

INTELLIGENCE INFORMATION CABLE

País: /Chile

DOI: [TACHADO] agosto 1973

Materia: Visión del comandante en jefe del ejército chileno sobre una posible intervención militar en su país

[TACHADO]

\footnotetext{
${ }^{21}$ Garcés, Joan. 1975. "Así cayó Allende", Triunfo, 5a. época, año XXX, 675, 6 de septiembre de 1975, p. 21.

22 Vega, L. 1983. "La caída de Allende. Anatomía de un golpe de Estado", cap. VI, N5; Varios, 2019. Testimonios de militares antigolpistas. Presentación y entrevistas de Jorge Magasich, Fuentes para la historia de la república, volumen XLVIII, Biblioteca Nacional de Chile - Centro de investigaciones Diego Barros Arana, Santiago, p. 1202.

${ }^{23}$ Cable 'umbra' de la DIA, 08.09.73, f.1; nsaarchive.gwu.edu/document/22019-document-03.
} 
[TACHADO]

[TACHADO] ... se reunió con un número de oficiales superiores, incluido el general Augusto Pinochet, comandante en jefe del ejército, y el general Orlando Urbina, jefe de estado mayor. [TACHADO] ....Reporta su encuentro con [TACHADO] ...El sostiene que su conversación con el general Pinochet fue muy franca y abierta, comentando que el último pareciera estar resignado a un eventual derrocamiento del gobierno por la fuerza, pero solo cuando todos los restantes caminos para resolver la situación del país estén cerrados. [TACHADO]... dijo que Pinochet parece estar aterrado por el fantasma de una matanza civil y afirma que el ejército como institución no puede emprender un golpe de estado hasta que una abrumadora mayoría del pueblo clame por tal acción. Pinochet comentó, además, que los partidos políticos deben pedir a los militares que intervengan, antes que él personalmente pueda consentir moverse contra el gobierno.

[TACHADO]... informó [TACHADO]...que no tuvo buena impresión del general Urbina y no confía en él. [TACHADO] Se habla... [TACHADO]... que Urbina fue izquierdista; lo cierto es que su actitud hacia Urbina puede estar reflejando sus prejuicios.

[TACHADO] también informa que la mayoría de sus [TACHADO] ...contactos en el ejército, expresan el temor que la actual lucha socio - política en el país pueda dañar la capacidad de Chile de defenderse a sí mismo de un posible ataque peruano, y/o de Bolivia. Estos oficiales discuten que el problema primario sería la falta de combustible y alimento, en caso que tal ataque tenga lugar. [TACHADO] comentó que duda de la seriedad de tales temores que ha escuchado expresar muchas veces. [TACHADO] ...comenta: sin embargo son justificados. Es creíble que los temores chilenos acerca de una invasión de Perú o Bolivia son reales. Estos temores giran alrededor de la presunción de que ambos países no podrían dejar pasar la oportunidad de tomar ventaja de la débil posición de Chile y recobrar los territorios que perdieron en la guerra del Pacífico.

[TACHADO4

Finalmente [TACHADO] ...dijo [TACHADO] que la Unión Soviética considera que la revolución chilena ha fracasado y está destinada a terminar mediante una acción militar. [TACHADO] ... agregó que uno no puede esperar que el socialismo prospere en el actual caos del país.

[TACHADO]

Fuente: Coup cables, box 777-778, National Security Council Files, Augusto Pinochet files, fs. 20-4 


\section{El diseño avanzado del golpe: fundación de la junta militar de gobierno, jefatura de A. Pinochet y cambio de fecha del putsch del 10 al 11 de septiembre}

[TACHADO] ... proporcionó la siguiente relación de antecedentes sobre la preparación del golpe de estado del 11 de septiembre.

A mediados de agosto de 1973 las fuerzas armadas iniciaron la preparación para derrocar al ex presidente Salvador Allende; para esta tarea organizaron un "equipo especial de coordinación", compuesto por tres delegados de cada servicio militar, con el rango máximo de general o almirante; posteriormente, civiles cuidadosamente escogidos, fueron incorporados en el equipo.

Este equipo de coordinación preparó el plan de derrocamiento del gobierno de la Unidad Popular (UP) y el 1 y 2 de septiembre fue explicado a los comandantes en jefe (CEJ) del ejército y de la fuerza aérea y al almirante José Medina. El plan fue aprobado por ellos, y se dieron órdenes de hacer los preparativos para emprender la acción el 10 de septiembre, a una hora que sería establecida por el general Pinochet, comandante en jefe del ejército, que fue elegido como jefe del grupo.

Por varias razones, particularmente por algunos problemas organizativos en la red de radio y televisión de las fuerzas armadas y carabineros, el golpe fue pospuesto hasta la madrugada del 11 de septiembre. El plan aprobado fue el siguiente:

Al amanecer del 11 de septiembre, la marina tomaría posesión de Valparaíso y Viña del Mar, y emitirá un ultimatum al presidente Allende:

La armada y la fuerza aérea (Fach) se acuartelarán en primer grado de alerta, a partir de las 7.30 A.M. del 11 de septiembre.

Los carabineros serían neutralizados por un nuevo director general, que sería el general César Mendoza. Mendoza ordenaría retirar los carabineros del palacio [la Moneda], de la oficina del intendente de Santiago y de la residencia presidencial de Tomás Moro. Además, carabineros daría apoyo a las fuerzas armadas.

Sería instaurada una junta de gobierno, compuesta por los tres comandantes en jefe y el director de carabineros, la cual funcionaría en el ministerio de defensa y desde allí, a las 9:00 AM, o cuando contacte a Allende, emitirá un ultimatum exigiendo la entrega del poder a ella.

En caso de resistencia del presidente y de la UP, las fuerzas armadas y carabineros actuarían enérgicamente; conforme a los planes previamente acordados.

Las acciones de las fuerzas armadas y de los carabineros serían dirigidas y coordinadas por personal del ministerio de defensa, emplazado en el quinto piso del ministerio, en donde estaría localizado el equipo coordinador. 
La red de las fuerzas armadas instalaría su puesto de mando en el quinto piso del ministerio de defensa, y tendría como base radio Agricultura y un canal de televisión perteneciente a la Universidad Católica (canal 13).

La guarnición de Santiago sería reforzada con batallones de los Andes, San Felipe, Río Blanco y Quillota, y con el grupo de artillería de Linares.

La fuerza aérea tendría libertad para reforzar Santiago con las bases del norte y del sur.

La marina tendría libertad para fortalecer sus instalaciones del sector de la Quinta Normal.

Los comandantes de división y de las guarniciones provinciales asumirían el control y el poder total en sus respectivas áreas.

5.[TACHADO] La ejecución del plan del 11 de septiembre tomó de sorpresa al gobierno de la U.P. Desde el golpe, la junta de gobierno se concentró en operaciones de limpieza de organizaciones terroristas y francotiradores de la U.P. La orden dada desde el 11 ha sido ejecutar a todo elemento subversivo que resista, sin excepción ni distingos a su nacionalidad o posición. Se calcula que estas operaciones estarían terminadas en Santiago alrededor del 15 de septiembre. En Santiago, la operación de limpieza está siendo dirigida por el comandante de la guarnición de Santiago.

6. [TACHADO]

FUENTE. Balance de la CIA de 16.09.73, desclasificado de: U. S. Department of State, Chile Declassification Project: (human rights in Chile-Tranche1), Washington, D.C., 1999. The Department of State, Freedom Of Information Act (FOIA), USA.

3. La embajada estadounidense confirma informes de inteligencias clave del $\mathbf{7}$ de septiembre que ratifican el acuerdo entre el general $A$. Pinochet, el general G. Leigh y el contralmirante P. Carvajal en orden a derrocar al gobierno de S. Allende el lunes $\mathbf{1 0}$ de septiembre

Situación: Chile

Materia: Golpe

Mensaje/Anotación

Anotaciones: La Embajada reporta un posible movimiento militar contra el gobierno; se asume que Allende está en conocimiento de los planes y hará cualquier maniobra disponible para protegerse.

Mensaje: inmediato

Sep 73

FM Embajada Santiago 
A: Secretario de Estado Washington D.C. NIACT inmediato 5447

[...]

Materia: Amenaza militar a la continuidad de Allende

Aprobado* por el embajador Davis

Resumen: El presidente falló en desactivar la crisis de la Armada relacionada con el reemplazo del comandante en jefe Montero y consistentes informes de inteligencia durante el 7 de septiembre indican serias amenazas militares a que Allende continue.

1. Las Informaciones clave de inteligencia son:

(A) Allende se reunió con Merino al mediodía del 7 de septiembre y trató de frenar el nombramiento de Merino como comandante en jefe de la armada hasta el martes 11 de septiembre, propuesta que los comandantes de la marina encuentran inaceptable. Esto, por cierto, deja a la marina a punto de inflamarse. Fuentes muy confiables de la armada informan que el 8 de septiembre puede ser el "día D" para el movimiento militar contra el gobierno. Información complementaria señala que los almirantes de la marina ya no debaten si [deben] actuar sino cuando -el 8 de septiembre, el 9 o el 10. (B) Fuentes de la fuerza aérea cercanas al comandante en jefe Leigh reportan la inestabilidad de la armada y citan: 'podríamos tener que movilizarnos en [su] ayuda'. El estado mayor de la fuerza aérea y la base de el Bosque en alerta. (C) Se reporta que el general Arellano, un complotador clave del ejército, afirma que ahora está listo para actuar, sugiriendo que tiene el firme respaldo de comandantes de regimientos clave. (d) El almirante Carvajal, jefe del estado mayor conjunto de la defensa, el comandante en jefe de la fuerza aérea y el comandante en jefe del ejército, Pinochet, se reunieron el 7 de septiembre por la tarde y acordaron actuar contra el gobierno a las 0800 del lunes 10 de septiembre, sea lo que sea que haga Allende.

(E) Informamos que grupos civiles de la extrema derecha, tienen planes para entrar en acción en Santiago el lunes 10 de septiembre, interrumpiendo las comunicaciones y escenificando demostraciones. Información complementaria, indica que las agencias de gobierno están en conocimiento de estas acciones en Santiago y en provincias, por parte de las brigadas juveniles de "Patria y Libertad" y del partido Nacional.

2. Dado el volumen y consistencia de la inteligencia que recibimos, debemos asumir que Allende también está en conocimiento de la amenaza militar y recurrirá a alguna maniobra para tratar de resguardarse.

Thompson

Fuente: Coup cables, box 1, National Security Council Files, Augusto Pinochet files, fs. 5 y 6. *En el texto figura pass, uso habitual cuando documentos confidenciales requieren el visto bueno del embajador antes de distribuirse. Con todo, ese día el embajador Davis se hallaba de visita en Washington, lo que abre dos posibilidades: $\mathrm{O}$ el cable se mandó con la autorización del alto 
funcionario de la repartición que Davis designó en su reemplazo mientras estaba en misión en los EE. UU., facultado a obrar por él; o pass estaría consignando la solicitud del remitente de transferirlo a Davis, para su toma de conocimiento. No está nada claro.

\section{Se confirma que los generales Pinochet y Leigh mantenían un acuerdo para el derrocamiento del gobierno de s. Allende el lunes 10 de septiembre de 1973.}

Dirección de operaciones de la CIA, cable con información de inteligencia, 07.09.1973, País: Chile

DOI: [TACHADO] SEPTIEMBRE 1973

Materia: Decisión de las fuerzas armadas chilenas de iniciar un golpe de estado el 10 de septiembre

[TACHADO]

1. [TACHADO] que conversó con el comandante en jefe del ejército, Augusto Pinochet, y el comandante en jefe de la fuerza aérea, Gustavo Leigh, en [TACHADO] septiembre, y ellos están de acuerdo en iniciar una acción militar contra el gobierno de Allende [TACHADO] el 10 de septiembre. Esta acción tendrá lugar aunque el presidente Salvador Allende decida remover al comandante en jefe, Raúl Montero, antes del 10 de septiembre y sea reemplazado por el almirante Montero (sic), comandante de la primera zona naval en Valparaíso. [TACHADO] comenta: el presidente Allende iba a reunirse con el almirante Merino, temprano en la tarde del 7 de septiembre, a discutir la posible remoción de Montero como comandante en jefe. La marina tenía expectativas de que Allende lo nombrara como comandante en jefe el 7 de septiembre. Esto, aparentemente, no sucederá.

2. [tachado]

Fuente: Coup cables, box 777-778, National Security Council Files, Augusto Pinochet files, fs. $30-$ 1.

\section{Referencias citadas}

Basso, Carlos. 2013. La CIA en Chile 1970-1973, Santiago, Aguilar.

Defense Intelligence Agency. 08.09.1973. Cable umbra, Disponible en:

nsaarchive.gwu.edu/document/22019-document-03.

Carvajal, Patricio. 1993, Téngase presente, Valparaíso, Arquén.

National Security Council. 1999. Files Coup cables, box 1, 777 y 778, Augusto Pinochet files. 
Davis, Nathaniel. 1986. Los dos últimos años de Salvador Allende, Barcelona, Plaza \& Janes.

Espinoza, Guillermo. 1998. "Allende. 25 años", en Especial de El Siglo, Santiago, 11/17 de septiembre de 1998, pp. 1-16.

Fontaine, Arturo y Zegers, Cristian. 1974. "Como llegaron las Fuerzas armadas a la acción del 11 de septiembre de 1973", suplemento de El Mercurio, Santiago, 11 de septiembre de 1974.

Garcés, Joan. 1975. "Así cayó Allende", en Triunfo, 5a. época, año XXX, N675, 6 de septiembre de 1975, España, pp. 21-29.

González Camus, Ignacio. 1988. El día en que murió Allende, Santiago, Cesoc.

González Mujica, Mónica. 2000. La conjura. Los mil y un días del golpe, Santiago, Ediciones B.

Huerta, Ismael. 1988. Volvería a ser marino, Santiago, Andrés Bello, 2 volúmenes.

Huidobro, Sergio. 1989. Decisión naval, Valparaíso, Impr. de la Armada.

Kornbluh, Peter. 2013. Pinochet. Los archivos secretos, Barcelona, Crítica (2a. Edición ampliada).

Leigh, Gustavo. 1998. "Pinochet no quería, temía por su vida", en Caras, año XI, N²72, 4 de septiembre de 1998, Santiago-Chile, pp. 41-42.

Letelier, Orlando, Garcés, Joan y Landau, Saul. 1995. Orlando Letelier. Testimonio y vindicación, Madrid, Siglo XXI.

Merino, José T. 1998. Bitácora de un almirante, Santiago, A. Bello.

Pérez Carrillo, D. 2006. "La fronda militar", en Documento de Trabajo, 82, septiembre, Inap Universidad de Chile.

Pinochet, Augusto. 1990. Camino recorrido. Memorias de un soldado, Santiago, Impr. del Instituto Geográfico Militar, tomo I.

Pinochet, Augusto.1999. Augusto Pinochet: Diálogos con su historia. Conversaciones inéditas con

María Eugenia Oyarzún, Santiago, Sudamericana.

Schnake, Erich. 2004. Schnake, un socialista con historia. Memorias, Santiago, Aguilar.

Soto, Hernán y Villegas, Sergio. 1999. Archivos secretos. Documentos desclasificados de la CIA, Santiago, LOM.

Téllez, Eduardo. 2021. Una guerra relámpago, Santiago, Mss. (manuscrito) inédito.

Toro, Carlos. 1995. "El general Prats pudo evitar el golpe”, en Especial de El Siglo, Santiago, 15 de septiembre de 1995, p. 8-9.

U. S. Department of State. 1999. Chile Declassification Project: (human rights in Chile-Tranche1), Washington, D.C., The Department of State, Freedom Of. Information Act (FOIA), USA.

Equipo editor de El Siglo. 1995. "11 de septiembre, operación militar", en Especial de El Siglo, Santiago, 15 de septiembre de 1995, p. 10.

Magasich, Jorge. 2019. Testimonios de militares antigolpistas. Presentación y entrevistas de Jorge Magasich, Fuentes para la historia de la república, volumen XLVIII, Santiago, Biblioteca Nacional de Chile - Centro de investigaciones Diego Barros Arana.

Marras, Sergio. 1988. Confesiones. Entrevistas de Sergio Marras. Federico Willoughby, Liliana Mahn. Mónica Madariaga, Gral. Nicanor Díaz E. Gral. Gustavo Leig, Santiago, Ornitorrinco.

Vega, Luis. 1983. Las dos Tácticas de la Contrarrevolución en Chile. Guerra Civil o Masacre Civil, en 
Vega, Luis, "La caída de Allende. Anatomía de un golpe de estado", Cap. VI, Rebelión. Disponible en Rebelion.org/docs/3254.pdf. Consultado el 02 de diciembre de 2021.

Whelan, James R. 1993. Desde las cenizas. Vida, muerte y transfiguración de la democracia en Chile 1833-1988, Santiago, Zig - Zag. 